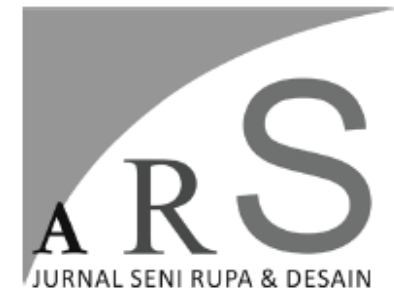

Volume 22 Nomor 2,

Agustus 2019

\title{
POTENSI TANAH LIAT GUNUNG MERAK DALAM PENGEMBANGAN DEKORASI ENGOBE DAN FINISHING GLASIR KERAMIK PAGERJURANG
}

\author{
Linda Nur Mastuti \\ Program Studi Kriya, Jurusan Kriya \\ Fakultas Seni Rupa, ISI Yogyakarta
}

\begin{abstract}
ABSTRAK
Penelitian ini bertujuan untuk mengetahui potensi tanah liat Gunung Merak dalam dekorasi engobe dan finishing keramik Pagerjurang. Pagerjurang itu sendiri merupakan sebuah nama desa vokasi keramik yang terletak di Kecamatan Bayat, Klaten. Hal menarik yang ada di Pagerjurang adalah finishing gerabahnya yang unik. Finishing tersebut disebut sebagai finishing irengan. Pagerjurang memiliki persoalan mengenai persaingan pasar keramik yang ketat. Setiap perajin membuat produk dengan desain yang sama tetapi harga berbeda. Selain itu saat ini kebutuhan akan variasi keramik baru di Pagerjurang meningkat dan pemanfaatan alat dan teknologi yang ada masih kurang maksimal, sehingga penelitian ini penting dilakukan agar mampu memberikan solusi serta memberikan variasi produk baru keramik Pagerjurang dengan tidak meninggalkan ciri khas tanah Pagerjurang, yakni menggunakan dekorasi engobe dan finishing glasir. Penelitian ini merupakan peneltian kualitatif dan kuantitatif menggunakan teori eksperimen dan action research dengan teortiteori keramik dan estetika sebagai pendukung dalam tahap penelitian. Hasil penelitian dianalisis sesuai teori keramik yang ada pada setiap proses eksperimen. Penelitian ini menunjukkan hasil dekorasi engobe dan finishing glasir pada tanah liat Gunung Merak yang diimplementasikan di prototype tableware. Sampel tanah liat Gunung Merak yang digunakan dicampur dengan tanah liat Sukabumi dengan perbandingan 3:2. Hasil dekorasi engobe yang diterapkan pada tanah liat sampel mampu menempel dengan baik pada permukaan tanah, selain itu kondisi engobe yang diterapkan memiliki hasil yang rata dan warna tidak kusam. Kemudian finishing glasir underglaze yang dilakukan menghasilkan efek bening pada tableware.
\end{abstract}

Kata Kunci: tanah liat, keramik Pagerjurang, engobe, dekorasi engobe, underglaze

\footnotetext{
ABSTRACT

This study aims to determine the potential of Mount Merak clay in engobe decoration and Pagerjurang ceramic finishing. Pagerjurang itself is a name of a ceramic vocation village located in Bayat District, Klaten. The interesting thing in Pagerjurang is the unique finishing of pottery. Finishing is referred to as finishing irengan. Less has problems regarding the tight competition in the ceramics market. Every craftsman makes a product with the same design but the price is different. Besides this, the need for new ceramic variations in Pagerjurang is increasing and the use of existing tools and technology is still not maximal, so this research is important to be able to provide solutions and provide new variations of Pagerjurang ceramic products without leaving Pagerjurang's distinctive characteristics, using
} 
decoration engobe and glaze finishing. This research is a qualitative and quantitative study using experimental theory and action research with ceramic and aesthetic theories as supporters in the research stage. The results of the study were analyzed according to ceramic theory that existed in each experimental process. This research shows the results of the decoration of engobe and finishing of glaze on the clay of GunungMerak which was implemented in a tableware prototype. The clay samples of Merak Mountain used were mixed with Sukabumi clay in a ratio of 3: 2. The results of the engobe decoration that is applied to the clay samples are able to stick well to the surface of the ground, besides the engobe conditions that are applied have a flat result and the colors are not dull. Then the underglaze glaze finishing which is done produces a clear effect on the tableware.

Keywords: clay, Pagerjurang ceramics, engobe, engobe decoration, underglaze

\section{Pendahuluan}

Tanah liat earthenware dan stoneware merupakan dua jenis tanah liat yang berbeda. Tanah liat stoneware memiliki warna terang, pori-pori kecil serta plastisitas tanah rendah. Berbeda dengan tanah liat stoneware, tanah liat earthenwarememiliki warna yang cenderung gelap, pori-pori tanah yang besar serta plastisitas tinggi, sehingga tanah liat earthenware sangat mudah dibentuk. Ketersediaan tanah liat earthenware di bumi begitu banyak, khususnya di Indonesia.(Astuti, 2008) Ada beberapa daerah yang memiliki tanah liat earthenware, yaitu di daerah Pagerjurang, Kasongan, Malang, Pundong, dan masih banyak lagi daerah lainnya.

Bayat merupakan salah satu daerah yang menyediakan sumber daya alam berupa tanah liat earthenware yang melimpah, seperti di Gunung Merak, Gunung Pandanaran, dan Gunung Malang, sehingga di daerah tersebut terdapat desa vokasi gerabah yang pada umumnya warga desa tersebut berprofesi sebagai perajin gerabah. Desa tersebut bernama Pagerjurang, terletak di Kecamatan Bayat Kabupaten Klaten. Pagerjurang sebenarnya terbagi menjadi dua wilayah kecamatan, setengah wilayahnya merupakan bagian dari Kecamatan Wedi dan setengah lainnya merupakan wilayah Kecamatan Bayat. Perajin gerabah tersebar acak di Pagerjurang Kecamatan Wedi dan Kecamatan Bayat.(Sariyono, 2018) Warga Pagerjurang umumnya hidup dari hasil membuat dan menjual gerabah.(Suharno, 2018) Mereka membuat berbagai macam perlengkapan rumah, seperti: alat memasak, peralatan makan, dan homedecor. Desain produk yang dihasilkan antar homeindustri di Pagerjurang tersebut hampir sama, namun masingmasing perajin memiliki pangsa pasar sendiri.

Perkembangan dalam industry keramik pada era sekarang konsumen memerlukan variasi produk dan finishing keramik yang baru, maka perlu dilakukan peningkatan kualitas produk tanpa meninggalkan ciri khas dari Pagerjurang dengan sumber daya alam tanahnya. Tanah Pagerjurang tersebut memungkinkan untuk ditingkatkan dengan dekorasi engobe dan finishing glasirnya atau dalam ilmu keramik disebut dengan underglaze. Guna meningkatkan kualitas produk Keramik Pagerjurang, perlu dilakukan penelitian mendalam untuk peningkatan kualitas bahan baku dan menghasilkan finishing baru pada produk-produk keramik Pagerjurang.

Uraian di atas dapat ditarik menjadi sebuah rumusan masalah bahwa apakah tanah liat Gunung Merak dapat digunakan sebagai bahan baku keramik dekorasi engobe dengan bakaran glasir suhu $1.150^{\circ}$ Celcius. Selain itu, bagaimana hasil penerapan dekorasi engobefinishing glasir suhu tinggi pada keramik Pagerjurang. Penelitian ini penting dilakukan untuk mengetahui kandungan tanah liat 
Gunung Merak yang nantinya akan dikembangkan dengan dekorasi engobefinishing glasir bakaran suhu tinggi. Hasil penelitian yang diperoleh akan dipilih dari sampel yang paling berpotensi, kemudian diterapkan pada produk keramik tablewarePagerjurang.

\section{Pembahasan}

\section{Keramik}

Keramik bercorak primitif ditemukan 4000 tahun yang lalu, berwarna hitam dan mudah pecah. (Hoge, Horn, 1986: 7) Keramik merupakan bahan-bahan tanah/batuan silikat dan yang proses pembuatannya melalui pembakaran suhu tinggi.(Astuti, 2008:1) Kamus ensiklopedia tahun 1950-an mendefinisikan barang dari tanah liat, seperti: genteng, gerabah, danporselin.

\section{Engobe}

Engobe merupakan suatu larutan tanah liat berwarna yang dilapiskan pada benda keramik dengan tujuan menutup dan mengubah warna asli tanah liat dengan tujuan dekoratif. (Astuti, 2008: 57)Finishingirengan gerabah di Pagerjurang juga menggunakan engobe. Engobe tersebut berbeda pada umumnya. Perajin di Pagerjurang menyebutnya sebagai lethoh(Sariyem, 2018), yaitu slip tanah liat berwarna merah yang diperoleh dari Gunung Pandanaran.

\section{Glasir}

Glasir merupakan suatu macam gelas khusus yang diformulasikan secara kimia, agar melekat pada permukaan tanah liat, atau melebur ke dalam badan waktu dibakar (Astuti, 1997:91). Finishing yang digunakan dalam dekorasi ini yaitu finishing glasir. Karena ini merupakan teknik underglaze,glasir yang digunakan untuk menutup dekorasi engobe yaitu glasir TSG atau glasir transparan, sehingga setelah dilakukan pembakaran dengan suhu tertentu akan berubah menjadi bening mengilat. Karena tanah yang digunakan dalam penelitian ini sudah dicampur dengan tanah liat Sukabumi, tanah Pagerjurang tersebut mampu dibakar suhu tinggi mencapai $1150^{\circ} \mathrm{C}$.

Metode Pendekatan yang digunakan dalam penelitian ini ialah pendekatan eksperimen, pendekatan action research, dan pendekatan estetika

\section{Pendekatan Eksperimen}

Pendekatan ini dilakukan percobaan-percobaan mengenai teknik dan dekorasi yang pas untuk tanah liat Pagerjurang. Percobaan ini dilakukan sesuai dengan teori-teori keramik yang ada. Eksperimen adalah suatu cara untuk mencari hubungan sebab akibat antara 2 faktor yang sengaja ditimbulkan oleh peneliti dengan mengeliminasi atau mengurangi faktor-faktor lain yang bisa mengganggu.(Arikunto, 2010:4)

\section{Pendekatan ActionResearch}

Penelitian ini dilakukan atas dasar tindakan-tindakan untuk melakukan percobaan pada tanah liat Gunung Merak.Actionresearch merupakan tindakan, eksperimen yang dilakukan terus-menerus dan terkontrol.(Arikunto, 2010:9) Teori yang digunakan dalam penelitian ini adalah teori actionresearch dari Arikunto yang nantinya dalam proses pengerjaannya didukung oleh teori-teori keramik yang ada.

\section{Pendekatan Estetika}

Penelitian ini juga menggunakan pendekatan estetika. Arti sebuah estetika adalah mengacu pada sebuah keindahan, baik secara audiovisual dan imajinatif. Memahami estetika sebenarnya menelaah forma seni yang kemudian disebut struktur rupa, yang terdiri atas unsur disain, prinsip desain dan asas desain.(Kartika, dan Perwira, 2004: 100)

Bayat merupakan daerah yang dikelilingi banyak Gunung. Gunung-gunung tersebut memiliki tanah yang umumnya berwarna merah. Pagerjurang memiliki populasi tanah liat yang digunakan sebagai bahan baku pembuatan kerramik sebanyak lima tanah liat. Tanah liat tersebut diperoleh 
dari beberapa daerah berbeda diantaranya: Gunung Merak, Gunung Pandanaran, Wiro, Kebon, dan Jotangan. Masing-masing tanah liat tersebut memiliki karakter yang berbeda.

Populasi tanah liat yang begitu banyak digunakan perajin di Paerjurang dipilih salah satu sampel. Sampel ini ditentukan berdasarkan hasil wawancara dengan beberapa perajin di Pagerjurang. Pertimbangan tersebut dilakukan karena perajin yang sangat dekat dengan sampel yang diambil. Sebagian besar perajin di Pagerjurang menggunakan tanah liat tersebut sebagi bahan baku untuk pembuatan keramik. Sampel yang diambil untuk dilakukan pengujian selanjutnya adalah tanah liat Gunung Merak. Perajin mengaku bahwa tanah liat Gunung Merak memiliki tingkat plasitisitas yang baik dibandingkan dengan tanah liat yang berasal dari daerah lain. Selain itu letak Gunung Merak yang bersandingan dengan daerah vokasi gerabah tersebut memudahkan perajin di Pagerjurang melakukan pengambilan tanah untuk dijadikan bahan baku.

\section{Analisis Sampel Tanah Liat Gunung Merak} Metode analisis data yang digunakan adalah metode analisis kualitatif dan kuantitatif. Metode tersebut dijelaskan bagaimana pengaruh dari perlakuan terhadap sampel yang dipilih. Sampel yang dipilih dari ketiga sampel yang ada adalah sampel kode M2. Sampel M2 merupakan campuran dari tanah liat murni Gunung Merak dan tanah liat Sukabumi. Persentase tanah liat yang digunakan adalah 3:2 dengan persentase tanah liat Gunung Merak lebih banyak dibandingkan tanah liat Sukabumi. Tanah liat kode M2 merupakan sampel yang paling baik karena memiliki plasititas yang tinggi serta susut tanah liat yang sedikit dibandingkan dengan sampel tanah liat lain.

\section{Analisis Engobe}

Formula engobekobe B2 merupakan campuran engobe yang paling baik hasilnya pada tanah liat Gunung Merak. Menurut teori pembuatan engobe dari Astuti, persentase setiap bahan harus sesuai, sehingga hasil yang diperoleh juga maksimal. Engobe yang baik adalah yang mampu menempel pada tanah liat dan jika diaplikasikan pada tanah akan berwarna dekken atau rata. Engobe kode B2 menunjukkan hasil mendekati dengan indikator engobe yang baik. Indikator engobe yang baik untuk diterapkan pada tanah liat, yaitu: dekken, tidak mengelupas, dan tidak transparan.

\section{Analisis Pembakaran Biskuit}

Proses ini ditemukan beberapa buah sampel prototipe tableware yang mengalami keretakan. Keretakan terjadi karena beberapa faktor, diantaranya keadaan tanah yang belum cukup kering saaat proses pembakaran, kurang maksimalnya penyambungan pada saat proses pembuatan dan tidak ratanya proses distribusi panas pada tungku.(Setiabudi, 2011: 92) Keretakan terjadi pada sambungan handle atau pegangan pada cups. Keretakan tersebut terjadi karena proses pengeleman yang kurng maksimal.

\section{Analisis Pembakaran Glasir}

Pembakaran glasir dalam penelitian ini dapat dikatakan kurang maksimal. Hal tersebut disebabkan karena masih adanya keramik yang belum matang sempurna, selain itu ada beberapa keramik yang glasirnya kurang merata. Hal ini dapat dianalisis dari penjelasan di atas bahwa akibat dari ketidaksempurnaan tersebut terletak pada penataan benda keramik yang kurang baik. Benda tidak ditata seragam dengan ukuran yang sama. Benda ditata acak untuk mengetahui tingkat perbedaan hasil pembakaran di setiap tingkatan plat. Setiap tingkatan plat memiliki suhu yang berbeda. Plat paling atas merupakan suhu paling tinggi, sedangkan plat di tengah dan seterusnya semakin ke bawah semakin rendah capaian suhunya. 


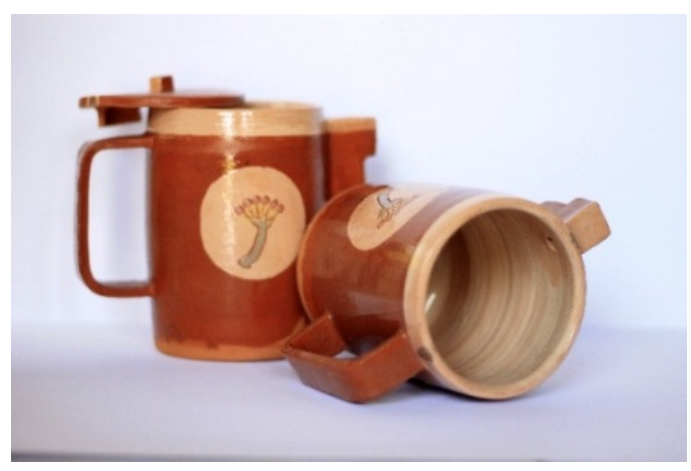

Gambar 1. Teko

(Sumber: Dokumentasi Penulis, Diambil oleh Linda Nur Mastuti, 18 Juni 2018)

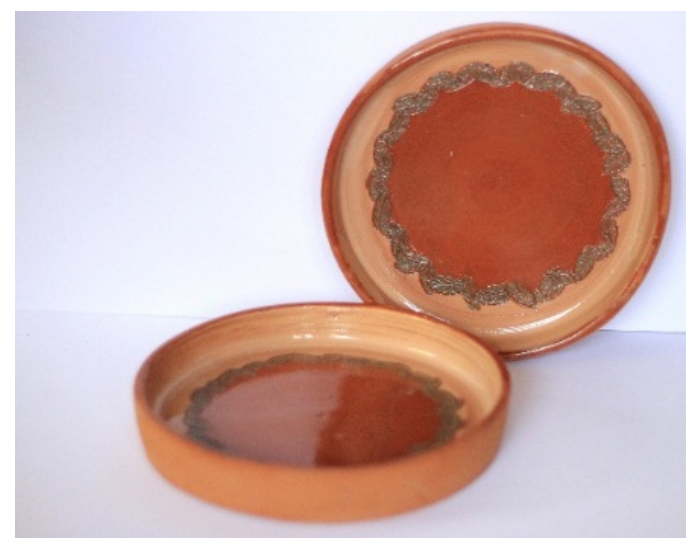

Gambar 2. Piring

(Sumber: Dokumentasi Penulis, Diambil oleh Linda Nur Mastuti, 18 Juni 2018)

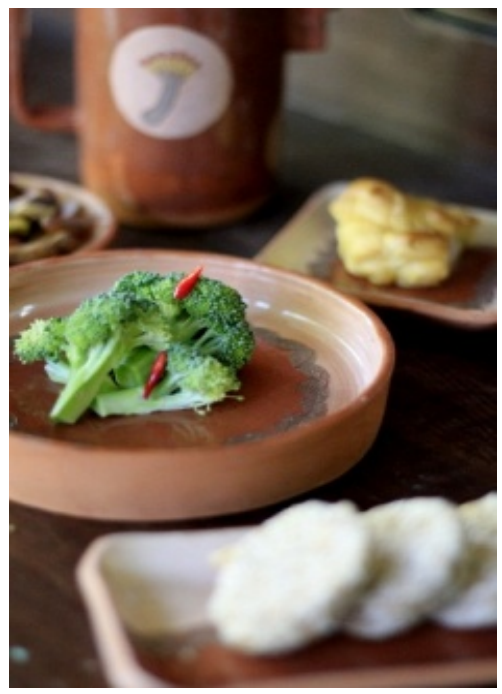

Gambar 3. CloseUpTableware

(Sumber: Dokumentasi Penulis, Diambil oleh Linda Nur Mastuti, 18 Juni 2018)

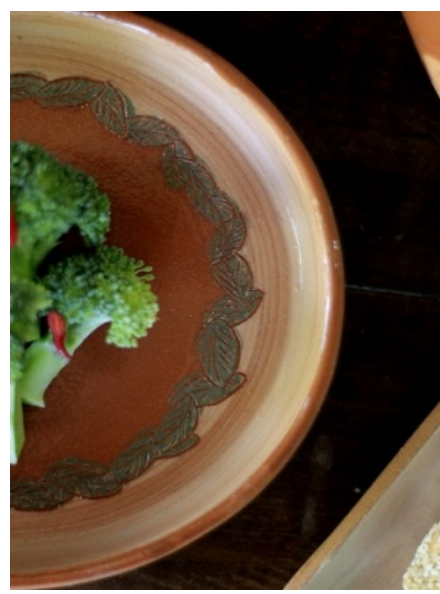

Gambar 4. CloseUp Ornamen

(Sumber: Dokumentasi Penulis, Diambil oleh Linda Nur Mastuti, 18 Juni 2018)

\section{Penutup}

Potensi tanah liat Gunung Merak dalam pengembangan dekorasi engobe dan finishing glasir dapat dilakukan dengan pemilihan sampel tanah yang tepat. Sampel tanah tersebut merupakan campuran dari tanah liat murni Gunung Merak yang dicampur dengan tanah liat Sukabumi. Persentasetakaran tanah liat yang dicampur adalah 3:2 dengan tanah liat Gunung Merak lebih banyak dibandingkan tanah liat Sukabumi. Sebelum proses pembuatan keramik, tanah liat tersebut harus disaring menggunakan mess 100 dengan tujuan untuk memisahkan antara kotoran, pasir, sehingga didapatkan kualitas tanah liat yang lebih plastis dan enak untuk dibentuk.

Engobe yang digunakan merupakan hasil percobaan beberapa sampel. Dari sampel tersebut diambil salah satu yang sudah memenuhi indikator engobebaik untuk diaplikasikan pada tanah liat Gunung Merak. Formula engobe yang digunakan adalah formula kode B2 dengan komposisi feldspar, kaolin, kuarsa, tanah liat bodi, ballclay, dan oksida secukupnya. Engobe tersebut mampu menempel dengan baik pada tanah liat Gunung Merak. Selain itu, kombinasi antara dekorasi engobe kuas dan sgrafito sesuai diaplikasikan pada tanah liat Gunung Merak. Campuran warna engobe putih dengan kombinasi warna dari oksida membuat keramik Pagerurang lebih estetis dipadukan 
dengan warna asli tanah yang coklat kemerahan atau gelap.

Finishing glasir transparan yang dilakukan pada penelitian terhadap potensi tanah liat Gunung Merak dibakar hingga suhu $1150{ }^{\circ}$ Celcius. Suhu tersebut merupakan suhu yang optimal untuk embakaran glasir produk keramik menggunakan tanah liat Gunung Merak. Karena jika dibakar pada suhu lebih dari $1150{ }^{\circ}$ Celcius, tanah akan mengalami deformasi bentuk.

Penelitian ini masih kurang maksimal karena dalam proses penelitian prototipetableware ada yang mengalami keretakan. Selain itu ada beberapa keramik yang pada pembakaran glasir kurang matang sempurna dikarenakan penataan benda yang kurang baik pada plat tungku.

\section{Daftar Pustaka}

Arikunto, S. (2010). Prosedur Penelitian: Suatu Pendekatan Praktek. Jakarta: Rinekacipta.

Astuti, A. (2008). Keramik Ilmu dan Proses Pembuatannya. Yogyakarta: : Jurusan Kriya Fakultas Seni Rupa: Institut Seni Indonesia Yogyakarta.

Hoge, Elisabeth. Horn, J. (1986). Keramik: Lengkap dengan Teknik da Rancangannya. Semarang: Dahara Press.

Kartika, Dharsono Sony dan Perwira, N. G. (2004). Pengantar Estetika. Bandung: Rekayasa Sains.

Sariyem. (2018). Wawancara "Proses Finishing Gerabah Pagerjurang."Wedi, Klaten.

Sariyono. (2018). Wawancara "Seputar Pagerjurang." Bayat, Klaten.

Setiabudi, N. (2011). Belajar Sendiri Membuat Keramik. Bandung: Bejana.

Suharno. (2018). Wawancara "Sejarah Pagerjurang." Bayat, Klaten. 